\title{
THE SUMMER NORTH ATLANTIC OSCILLATION IN CMIP3 MODELS AND RELATED UNCERTAINTIES IN PROJECTED SUMMER DRYING IN EUROPE
}

\author{
Ileana Bladé ${ }^{1,2}$, Didac Fortuny ${ }^{1}$, Geert Jan van Oldenborgh ${ }^{3}$ and Brant Liebmann ${ }^{4}$
}

Submitted to Journal of Geophysical Research (March 22, 2012)

Revised (June 15, 2012)

Final Revision (July 9, 2012)

1. Departament d'Astronomia i Meteorologia, Universitat de Barcelona, Barcelona, Spain

2. Institut Català de Ciències del Clima (IC3), Barcelona, Spain

3. Royal Dutch Meteorological Institute, De Bilt, Netherlands

4. NOAA/Earth System Research Laboratory, and CIRES Climate Diagnostics Center, Boulder, Colorado 
This paper discusses uncertainties in model projections of summer drying in the Euro-Mediterranean region related to errors and uncertainties in the simulation of the summer NAO. The SNAO is the leading mode of summer SLP variability in the North Atlantic/European sector and modulates precipitation not only in the vicinity of the SLP dipole (northwest Europe) but also in the Mediterranean region. An analysis of CMIP3 models is conducted to determine the extent to which models reproduce the signature of the SNAO and its impact on precipitation and to assess the role of the SNAO in the projected precipitation reductions. Most models correctly simulate the spatial pattern of the SNAO and the dry anomalies in northwest Europe that accompany the positive phase. The models also capture the concurrent wet conditions in the Mediterranean, but the amplitude of this signal is too weak, especially in the east. This error is related to the poor simulation of the upper-level circulation response to a positive SNAO, namely the observed trough over the Balkans that creates potential instability and favors precipitation. The SNAO is generally projected to trend upwards in CMIP3 models, leading to a consistent signal of precipitation reduction in NW Europe, but the intensity of the trend varies greatly across models, resulting in large uncertainties in the magnitude of the projected drying. In the Mediterranean, because the simulated influence of the SNAO is too weak, no precipitation increase occurs even in the presence of a strong SNAO trend, reducing confidence in these projections.

\section{1) Introduction}

Credible projections of future climate change on a regional scale require validation of the results via comparison with observations and assessment of consistency with theoretical arguments. For precipitation, however, there is little theoretical basis for expecting a change of a particular sign in a given region, except for the simple (yet fundamental) argument that the pattern of moisture flux convergence should amplify in response to warming temperatures, simply as a consequence of the Clausius-Clapeyron equation under constant relative humidity [Held and Soden, 2006]. This "wet gets wetter, dry gets dryer" mechanism should lead to decreased 
precipitation in subtropical areas, particularly ocean basins, where the largest moisture export occurs. Yet, in climate model simulations of the $21^{\text {st }}$ century, the most pronounced and robust precipitation changes in the northern subtropics occur over land, in the Mediterranean region, where the models almost unanimously project substantial reductions in precipitation, particularly in summer, when the drying extends to northwest Europe [Fig.1; see also van Ulden and van Oldenborgh, 2006; Meehl et al., 2007; Giorgi and Coppola, 2007; Scheff and Frierson, 2012]. Furthermore, a posteriori arguments invoking the poleward expansion of the Hadley cell observed in CMIP3 models - and the concomitant expansion of the subtropical dry zone (Lu et al., 2007) do not seem particularly relevant to the Mediterranean region in summer. Indeed, not only is the signature of the Hadley circulation confined to the eastern Mediterranean, but most of the subsidence that prevails in that region appears to be primarily driven by the Asian monsoon [Rodwell and Hoskins, 1996; Ziv et al., 2004]. Comparison of model projections with recent observed trends of summer precipitation, as a means of increasing our confidence in these projections, is also non-conclusive as the trends are weak and not statistically significant (for either the full record or the last 60 years) [Bladé et al., 2011; van Haren et al., 2012].

The model agreement regarding the sign of future precipitation changes may be due to common, well-represented processes, such as soil-moisture feedbacks [Rowell and Jones, 2006], but has not been investigated in depth and could plausibly be due, instead, to systematic biases in the models. One avenue to rule out this possibility and to validate the precipitation projections would be to explore whether the large-scale circulations that modulate precipitation in the EuroMediterranean region are correctly represented in these models - although these mechanisms themselves have not been extensively studied.

Recently, the summer manifestation of the North Atlantic Oscillation, or SNAO, has been identified as a major driver of precipitation (and also temperature) variability in large parts of Europe and the Mediterranean region [Mariotti and Arkin, 2007; Folland et al., 2009; Chronis et al., 2011; Bladé et al., 2011]. Compared to its winter counterpart, the SNAO is weaker, more 
spatially confined and its southern lobe is displaced northeastward into the UK and southern Scandinavia, so that strong anticyclonic conditions prevail in these regions when the SNAO is in the positive phase. As a result, the SNAO directly and strongly influences precipitation in this sector, where dry conditions are experienced during positive SNAO summers. Somewhat surprisingly given its northern location, a positive SNAO also significantly enhances rainfall in the Mediterranean region, particularly the Balkans and Italy, where it accounts for between 20 and $35 \%$ of the interannual variance. Bladé et al. [2011; hereafter B2011] have argued that this influence occurs via a downstream hemispheric upper-level circulation that develops in association with the SNAO and is characterized by a well-defined trough centered over the Balkans during the positive SNAO phase. The trough entails mid-tropospheric cooling and increased potential instability and thus leads to enhanced rainfall in the Mediterranean region.

B2011 also investigated the realism of the SNAO in two climate models, GFDL-CM2.1 and HadCM3. These models were able to accurately reproduce the spatial pattern and local impact of the SNAO over northwest Europe but not the remote influence in the eastern Mediterranean, which was weak or almost nonexistent. The error was tracked to the models' inability to correctly capture the upper-level SNAO-related circulation. Moreover, because both models projected a strong upward SNAO trend in the future, the error in the surface SNAO signature then impacted the projected precipitation trends in the Mediterranean region, since the expected increase in precipitation, linearly associated with the SNAO trend, did not take place. These two models were chosen because of their realistic SNAO pattern and pronounced future SNAO trend but it is not known the extent to which this behavior is common to all models. On the other hand, Giorgi and Coppola (2007) have shown that the CMIP3 multi-model mean pattern of future summer SLP change displays increased pressure over the British Isles and decreased pressure in Greenland. This result suggests that the SNAO may indeed exhibit a future upward trend in most models, which would account for some of the consistent projected drying in northwest Europe.

The goal of this paper is to document CMIP3 model performance with regards to the SNAO and 
to assess the contribution of SNAO trends to projections of precipitation in the Euro-Mediterranean region. We will show that many CMIP3 models correctly capture the spatial features of the SNAO as well as the strength of the associated rainfall anomalies in northwest Europe. Models also reproduce the widespread increase in precipitation in the Mediterranean that occurs during the positive SNAO phase, but the effect is consistently too weak. We also show that the future SNAO trend, and thus the part of the precipitation change that depends on this trend, varies considerably from model to model, although the trend is generally positive. Thus the SNAO emerges as an important contributor to intermodel consistency but also a large source of uncertainty in northwest Europe and a potentially large source of error in the Mediterranean.

\section{2) Data and methodology}

The observational analysis is based on the $5^{\circ} \times 5^{\circ}$ gridded Trenberth SLP dataset [Trenberth and Paolino, 1980], covering the period $1899-2011$, the $2.5^{\circ} \times 2.5^{\circ}$ global reconstructed PREC

precipitation dataset (1948-2011) developed at NOAA CPC (available at http://www.esrl.noaa.gov/psd/data/gridded/data.prec.html) and NCEP/NCAR reanalysis 200-hPa geopotential height data. Over land, the PREC dataset is based on optimal interpolation of raingauge data, while over oceanic regions estimates are based on an EOF reconstruction of land gauge observations [Chen et al., 2002; 2004; Janowiak et al., 2003].

For model data, we use all available sequential 20C3M/SRESA1B simulations from the Coupled Model Intercomparison Project Phase 3 (CMIP3) developed for the IPCC AR4. Data for the individual 20C3M and SRESA1B runs were downloaded from the CMIP3 multi-model database (https://esg.llnl.gov:8443/index.jsp) and spliced into consecutive simulations extending from 1900 to 2099 (the common period to all runs), using the information contained in the metadata. At the start, all available simulations were used, except run 1 of GISS-ER, run 3 of ECHO-G and run 9 of CCSM3 (problems where found either in the metadata or in the data that prevented us from confidently concatenating the runs). In addition, we retrieved two 
supplementary GFDL-CM2.1 extended runs from the GFDL data portal (run 1 and run 3). In total, 24 models and 56 simulations were used at the onset (Table 1). Information on the models can be found at:

http://www-pcmdi.llnl.gov/ipcc/model_documentation/ipcc_model_documentation.php .

All model data were re-gridded to a common grid $\left(2.5^{\circ} \times 2.5^{\circ}\right.$ for $\mathrm{SLP}, 0.5^{\circ} \times 0.5^{\circ}$ for precipitation) using bi-linear interpolation to facilitate model and observational data comparison. To avoid possible contamination from long-term trends, $20^{\text {th }}$ century data are detrended prior to computing regressions and correlations. The results obtained, however, are very similar if undetrended data are used instead. Multi-model ensemble quantities are obtained by first averaging over all available ensemble members for each model and then averaging over all models, so that all models are given equal weight even if the number of ensemble members differs.

All analyses are based on anomalies from the July-August mean, computed by subtracting the corresponding climatological long-term mean. EOFs are calculated as the eigenvectors of the area-weighted covariance matrix. To obtain (asymmetric) 95\% confidence limits for linear correlation coefficients, a non-parametric bootstrap method is applied, in which 1000 independent pairs of data samples, with replacement, are drawn and an empirical distribution of the statistic is estimated (in some instances, for brevity, the $95 \%$ confidence interval is quoted as a symmetric interval, using the largest of the two deviations). Linear trends are estimated as the slope of a straight line fitted to the data, in a least-square sense. Trend significance is determined using a Monte Carlo technique (10000 random permutations of data).

To compute ensemble-mean or area-mean correlations from a set of correlations with identical temporal sample size (which are not normally distributed and are therefore not additive), we apply a Fisher- $Z$ transformation to each correlation value: $Z=\operatorname{atanh}(r)$. These $Z$ values are approximately normally distributed, have equal standard deviations and can thus be averaged 
linearly [Wilks, 2006; Faller, 1981]. The resulting mean Z-value is inverse-transformed to yield an unbiased estimate of the average correlation.

\section{3) The simulated SNAO pattern compared to observations}

In B2011, the summer NAO was defined as the leading EOF of mean July-August ("highsummer") SLP in a restricted North Atlantic domain $\left[40^{\circ} \mathrm{N}-70^{\circ} \mathrm{N}, 90^{\circ} \mathrm{W}-30^{\circ} \mathrm{E}\right]$, following recommendations by Folland et al. [2009; hereafter F2009] and Greatbatch and Rong [2006]. Because, prior to 1940, the SNAO pattern appeared weak and non-robust (likely because of the scarcity of Greenland data), a "baseline" SNAO was defined as the pattern obtained for the period 1950-2010. For this period, the leading EOF mode is robust, well separated from the second mode [North et al., 1982] and virtually identical in observational and NCEP reanalysis data. Thus specified, the SNAO is characterized by a SLP dipole with a SW/NE orientation, centers of action of comparable amplitude over Greenland and the UK and is such that, in the positive phase, anticyclonic conditions prevail over NW Europe (Fig. 2, inset). In this and the bottom maps, the EOF is displayed in terms of the regression between its normalized detrended principal component (PC) and SLP anomalies at every grid-point.

To compare the simulated patterns of variability with the observed leading pattern, an identical EOF analysis of July-August SLP is performed for every individual simulation, also for the 1950-2010 period. Except in two simulations, the two leading EOFs are well separated from each other and the dominant mode generally consists of a north-south dipole, with the northern lobe situated over Greenland. The location of the southern lobe, however, is variable, with some models tending to position it west of the UK or even in the center of the Atlantic (e.g., IPSL-CM4, Fig. 2, bottom right). In a few simulations, the mode that most closely resembles the SNAO pattern is the second EOF (e.g., HadGEM1, consistent with F2009). Even when the simulated pattern is close to the observed, there may be large differences in the strength of the associated SLP anomalies, with the percent of explained variance ranging from $16 \%$ (GISS-AOM) to $50 \%$ (PCM), compared to $35 \%$ (observed). [The reader is referred to Table 1 for complete information 
on the SNAO in all simulations].

The resemblance between the simulated and observed patterns can be quantified by calculating the spatial anomaly correlation $\left(r_{s}\right)$ between the model's closest analog of the SNAO (generally EOF1) and the observed pattern, together with the normalized magnitude relative to the observed pattern, or root-mean-square - rms - amplitude ratio, $A=\left(\sum_{i=1}^{N} m_{i}^{2} / \sum_{i=1}^{N} o_{i}^{2}\right)^{1 / 2}$

where $\mathrm{m}_{\mathrm{i}}\left(\mathrm{o}_{\mathrm{i}}\right)$ indicates the model (observed) EOF at the $\mathrm{N}$ grid-points. The calculation is weighted by latitude and is applied to the unweighted EOFs (which coincide with the SLP regressions in the domain in which the EOFs are computed). The results are plotted in Taylor-diagram format [Taylor, 2001] in Fig. 2, for all individual simulations (the actual values as well as the ensemblemean values can be found in Table 1. Note that, unlike a true Taylor diagram, the radial coordinate is the ratio of the rms amplitude, following Shin and Sardeshmukh [2010], not the ratio of the standard deviations).

Overall, the models produce an SNAO-like mode with a reasonably good spatial correspondence with the observed pattern: many simulations exhibit anomaly pattern correlations greater than 0.75 and normalized rms magnitudes between 0.75 and 1.25 , and in a few simulations these values even approach unity. In general, model skill is consistent across simulations, with a given model uniformly performing well or poorly. In particular, ECHAM5, GFDL-CM2.1, CCSM3 and PCM, each with three or more runs, systematically reproduce the observed pattern $\left(r_{s} \geq 0.75\right)$, although both NCAR models tend to greatly overestimate the magnitude of the northern center of action $(A>1.25)$. The best performing simulation, by our two metrics, is the single CSIRO-MK3.5 run $\left(r_{s}=0.94, A=1.06\right)$, whose pattern is shown in the bottom left panel of Fig. 2 . The models with the worst overall performances $\left(r_{s} \leq 0.5\right)$ all display westward-displaced and 
generally weak dipoles (all three GISS models, FGOALS, ECHO-G, INM-CM3.0 and IPSL-CM4, shown in Fig. 2. The complete set of patterns is shown in Fig. S1).

The above analysis indicates that many models approximately reproduce the spatial pattern of the leading mode of summer SLP variability, albeit with variations in strength and in the exact location of the anti-nodes. Moreover, in some cases, the SNAO is only slightly shifted west (i.e., GFDL-CM2.0, Fig. S1), which substantially lowers the spatial correlation with the observed pattern, but still results in a substantial precipitation impact over northwest Europe (Fig. S2). Since we are concerned with assessing the surface influence of simulated SNAO-like variability in Europe, hereafter we opt for a fixed-pattern approach, in which the observed "baseline" EOF pattern is projected onto the SLP field of each simulation and the resulting projection coefficient time series (or pseudo-PC) is considered the SNAO index for that run. This strategy attempts to ensure that we compare the impact of the same circulation pattern and reduces the effect of model biases (e.g., too much variability in the central North Atlantic) that may result in erroneous representations of the leading EOF despite the presence of realistic dipolar SLP variability in the northeast Atlantic (it also eliminates the occasional problem of poor separation between EOFs).

We can assess whether the observed pattern is actually present and prominent in a given simulation by examining the pattern of regressed SLP anomalies against the normalized pseudo-PC. Based on both a visual inspection and the spatial anomaly correlation with the observed pattern $\left(r_{s}\right)$, we rejected the GISS-AOM, IPSL-CM4 and FGOALS models because, even when using an index determined by a projection onto the observed SNAO pattern, the resulting regression does not resemble the SNAO $\left(r_{s}<0.8\right.$, column 11 in Table I). We also discarded GISS-ER and ECHO-G, for which no complete 20C3M/SRESA1B precipitation or geopotential height data were available. This left us with 44 CMIP3 simulations from the best 19 models, based on the SNAO metric. This good agreement can be illustrated by comparing the observed and multi-model mean SNAO patterns, 
which are quite similar in both spatial structure and strength (Figs. 3a-b). To provide a proper comparison, the pattern is computed in terms of correlations between the SNAO time series and SLP at every grid-point, which eliminates the influence of differences in SLP variance between models and observations. Additionally, for the multi-model mean, all correlations maps were averaged in Fisher-Z space and the resulting mean $\mathrm{Z}$ map was inverse-transformed to derive an average correlation map.

An often-cited disadvantage of the fixed-pattern projection approach is that the SNAO pattern used maximizes the fraction of explained variance in observations but not so in the models [Osborn, 2004; see also Table 1]. However, since we are not interested in the fraction of variance explained by the SNAO (which, as noted earlier, is greatly overestimated in some models), this issue is not of great concern, more so since we will only consider correlations between the SNAO index and other variables. At any rate, we note that our results are not qualitatively altered if each model's own SNAO pattern is used instead (except the models fare worse when compared to observations). This conforms with the result that the correlation between the pseudo SNAO PC and the actual PC exceeds 0.9 in half of the simulations and is less than 0.8 for only nine of the simulations (Table 1).

\section{4) The simulated SNAO precipitation signal compared to observations}

We now investigate the extent to which CMIP3 models capture the observed precipitation signature of the SNAO in the Euro-Mediterranean sector. Figure 3c shows the observed correlation between the SNAO index and July-August mean precipitation. In order to facilitate the visual comparison with the corresponding simulated patterns and to de-emphasize minor shifts in their location, we use the combined land/ocean reconstructed precipitation PREC dataset. The corresponding land-only pattern one obtains using higher-resolution data (e.g., E-OBS) is consistent with the complete pattern shown herein and can be found in B2011 (their Fig. 5a). The PREC dataset shows that the signal of enhanced precipitation in the Balkans, Italy and Iberia that 
occurs during the positive SNAO phase covers the entire Mediterranean area and even extends to the eastern subtropical Atlantic and Black sea, while the concurrent dry conditions in NW Europe are most pronounced over the British Isles and southern Scandinavia.

The corresponding multi-model mean correlation map is shown in Fig. 3d. The north/south dipolar precipitation response to the SNAO is surprisingly well reproduced, including the SW/NE orientation of the dry anomalies in northwest Europe and the widespread pattern of wet anomalies that encompasses the entire Mediterranean region and beyond. The simulated Mediterranean signal, however, is much too weak in the east, with maximum correlations less than 0.3 ; in comparison, observed values exceed 0.6 over Italy and Greece. Accordingly, while in the north the multi-model mean correlation map captures the enhanced signal over the UK, in the south the largest simulated positive correlations occur over the Iberian Peninsula, in stark contrast with the observed pattern, which maximizes over the eastern Mediterranean. What is more, many models that produce a very realistic SNAO pattern with strongly suppressed precipitation in NW Europe fail to reproduce the concomitant wet conditions in the eastern Mediterranean (e.g., PCM, CSIROMK35 and HadCM3; see Fig. S2 for the complete set of SNAO/precipitation regressions).

To illustrate the variation of the SNAO signal among the models in a compact manner, while avoiding the limitations of areal averages, we consider the two ends of the distribution by stratifying the individual precipitation correlation maps according to their average magnitude over northwest Europe $\left(\mathrm{NWE} ; 50^{\circ} \mathrm{N}-65^{\circ} \mathrm{N}, 10^{\circ} \mathrm{W}-15^{\circ} \mathrm{E}\right)$ and southeast Europe/Mediterranean $\left(\mathrm{SEM} ; 35^{\circ} \mathrm{N}-50^{\circ} \mathrm{N}\right.$, $10^{\circ} \mathrm{E}-35^{\circ} \mathrm{E}$; see Fig. 1) and then selecting the 9 simulations with the strongest and weakest signal in each of those regions. For models with more than one ensemble member, we use only one member, that with the largest or lowest value, respectively, in order to show the models in their most/least favorable light (but recall that the very worst models have already been discarded). We then average the 9 chosen correlations maps (again, using a Fisher's Z transform). These high-end and low-end regional precipitation responses will be referred to as "strong" and "weak" responses and are shown in Fig. 4 (middle panel). Corresponding SLP correlations maps are also computed and shown in the 
top panel.

All four high- and low-end responses show strongly suppressed precipitation in NW Europe, as expected from the presence of an anticyclone aloft, even when it is relatively weak (Fig. 4e), and all exhibit a weaker pattern of positive precipitation anomalies that covers the entire Mediterranean region. The latter was not necessarily to be expected and indicates that most simulations (even the worst ones) capture the sign of the response correctly in this region also (see also Fig. S2). However, while the best simulations over NWE exhibit correlations almost as strong as the observed (Fig. 4f), the SEM response is weaker than observed even in the simulations that perform the best in this region (Fig. 4h, maximum correlations below 0.4). Moreover, even in this optimal case, the spatial distribution of the observed signal, with maximum amplitude in the eastern Mediterranean, is not correctly reproduced. The intensity of the UK anticyclone and of the rainfall anomalies over Iberia is comparable in both "strong SEM" and "weak SEM" correlation maps, indicating that the magnitude of the simulated precipitation response in the eastern Mediterranean is not related to the strength of the SNAO and also appears to be decoupled from the response over Iberia (Figs. 4c-d-g-h). Instead, the wet anomalies over Iberia tend to vary in parallel with the dry anomalies in NWE, which in turn scale linearly with the strength of the SNAO anticyclone (Fig. 4a-b-e-f; this is more apparent in corresponding regression maps, not shown).

The extreme response maps above allow visualization of differences in spatial structure and not just discrepancies in intensity in a specific region, but only for a subset of simulations. To provide a more comprehensive and quantitative comparison between the simulated and observed SNAO precipitation signals we also computed the correlation between the SNAO index and mean precipitation in those regions. In the NWE region, the observed value of $-0.86 \pm 0.08$ lies within the range of simulated values (albeit at the far end), with virtually all runs exhibiting correlations stronger than -0.5 (Fig. 5 and Table 1). For the Mediterranean region, we use a smaller box than the SEM box $\left(10^{\circ} \mathrm{E}-30^{\circ} \mathrm{E}, 37.5^{\circ} \mathrm{N}-45^{\circ} \mathrm{N}\right.$ - i.e., the Italy/Balkan region used in $\mathrm{B} 2011$ and depicted in Fig. 
1), in order to narrow in on the area of largest observed positive precipitation/SNAO correlations. In contrast with the NWE region, no simulation matches or exceeds the observed value of $0.65 \pm 0.15$ and a third of the runs exhibit correlations of 0.2 or weaker (or even negative), including models with an otherwise realistic SNAO, such as CSIRO-MK3.5, HadCM3 and PCM (which are all part of the "weak SEM response" subset, see Table 1). The fact that the latter two have relatively coarse horizontal grids (T42) raises the possibility that their poor skill in simulating the SNAO influence on Mediterranean summer convection might be related to insufficient resolution. Examination of other models, however, reveals little support for this hypothesis. For instance, model MRI-CGCM2.3.2C, the best performing model in the SEM region, with all five simulations displaying correlations larger than 0.4 (Fig. 5), is also T42 resolution.

A more promising hypothesis involves the role of the upper-level circulation in creating favorable conditions for convection. B2011 examined the regressed 200-hPa height anomalies associated with the observed SNAO and found that an upper trough centered over the Balkans during the positive SNAO phase was consistent with enhanced precipitation in that region via mid-level cooling and increased potential instability (as diagnosed with the surface lifted index). This link between the SNAO and the 200-hPa circulation is even more apparent in the correlation maps presented here, with correlations of up to -0.7 in the Balkan trough (Fig. 3e; see also composites in [Ossó et al., 2011], computed for a shorter period). Note also the strong spatial correspondence between the positive precipitation and the negative 200-hPa height anomalies across the Mediterranean region, which extends to the subtropical Atlantic (Figs. 3c-e). In agreement with the notion that an upper-level trough aloft is a critical factor for producing wet conditions in the eastern Mediterranean, the two CMIP3 runs examined in B2011, which lacked a realistic precipitation SNAO signal in that region, did not correctly reproduce the observed trough.

We now further test this hypothesis by comparing the observed correlation between the SNAO and the 200-hPa geopotential field with the model counterpart. The multi-model mean (Fig. 3f) exhibits negative upper level heights in the Mediterranean region extending into the 
subtropical Atlantic, with a double maximum structure that is reminiscent of the observations (Fig. 3e). However, and mirroring the differences between the observed and simulated precipitation responses, these negative anomalies are much less pronounced than in observations, with the trough over the Balkans appearing as the secondary rather than the primary feature, narrower in meridional extent and shifted south. These errors are reduced (exacerbated) in the simulations that exhibit the strongest (weakest) SNAO-related positive precipitation anomalies in the SEM region (Fig. 4k-1). The height correlation differences between strong and weak responses are modest, in keeping with the finding that, even in the best simulations, the SNAO precipitation signal in this region is too weak. Nevertheless, inasmuch as there is a more prominent and better-positioned trough in the simulations with the strongest precipitation signal, these results support our observational finding that the upper-level circulation is instrumental in driving the precipitation response to the SNAO in the SEM region. The precipitation anomalies over Iberia, instead, exhibit a less direct relationship with the strength of the 200-hPa height anomalies, which is consistent with the fact that this region is sandwiched between the eastern Atlantic and eastern Mediterranean troughs and thus under the influence of both (Fig. $3 \mathrm{f}$ and 4i-j-k-1).

As a final check for the above hypothesis, we consider the alternative possibility that the weak precipitation response to the SNAO may be due to a weak link between upper level circulation and precipitation in the models. We thus present scatter plots of the precipitation response to the SNAO in the Balkan/Italy region versus the strength of the precipitation response to a given Z-200 anomaly (Fig. 6a) and also versus the strength of the SNAO-induced Z-200 trough (Fig. 6b). The simulated positive precipitation anomaly associated with the presence of a 200-hPa trough aloft (y-axis) varies across models but tends to be weaker than in observations (though not overly so), with very few exceptions, in particular the two GFDL models (Fig. 6a). In fact, in these two models the sensitivity of precipitation to a $200-\mathrm{hPa}$ trough is so high that the regressed SNAO precipitation signal is strong despite the fact that the SNAO-induced trough is actually quite small (Fig. 6b). Still, the weak precipitation response to troughing aloft in most of 
the other models is consistent with the notion that, in nature, orographic uplift, along with enhanced moisture fluxes supplied by the warm summer local SSTs, favors the release of the potential instability created by the cold mid-tropospheric conditions (B2011). The models have much reduced orography and poorly resolved seas compared to the real world and hence underestimate this response in general. At the same time, there is no evidence of a systematic relationship between the strength of this precipitation response to upper-level height anomalies and the strength of the precipitation response to the SNAO, beyond the two GFDL models (the apparent correlation of -0.35 vanishes when the 4 GFDL data points are removed). The main reason for the discrepancy between the simulated and observed SNAO impact on precipitation in the Balkan/Italy region must then be the magnitude of the SNAO-induced trough, as suggested by Fig. 4k-1 and confirmed by the scatter plot in Fig. $6 \mathrm{~b}(r=-0.36)$.

Thus, capturing the modulating influence of the SNAO in the Mediterranean region requires an accurate simulation of the SNAO downstream wavetrain and, specifically, a properly positioned and strong enough trough over the Balkans. This in turn may depend on a correct representation of the summer extratropical jetstreams and associated Rossby waveguides, particularly the North African jet entrance region. Further investigation of this issue is planned with the new and improved CMIP5 experiments.

\section{5) Relationship between the SNAO trend and projected drying in Europe}

We now show that many CMIP3 models predict that the summer NAO will experience an upward trend in the future and consider the impact of this trend. To illustrate the former simply, without recourse to a pattern projection or an EOF analysis, we present in Fig. 7 the multi-model mean differences in July-August SLP between the second half of the $21^{\text {st }}$ century and the second half of the $20^{\text {th }}$ century. To remove any spurious global SLP trend (such as the well documented negative drift in the HadCM3 model [F2009], but also an equally large positive drift in the MIROC models), we subtract the global mean SLP in all simulations, following Osborn [2004]. 
The resulting difference pattern clearly projects onto the observed SNAO structure, with pressure increases over the UK and decreases over Greenland, implying a positive SNAO trend, on average, in the models. The reduced pressure over the Mediterranean in the CMIP3 models is associated with the development of a heat low [Haarsma et al., 2009]. The pattern of SLP change is consistent with that shown in Giorgi and Coppola [2007], for the entire summer season (JJA) and different time slices.

The actual SNAO trend, estimated for the period 2010-2099 by again projecting the observed SNAO pattern onto the models' SLP field and computing the linear regression of the resulting time series, is indeed positive in most of the simulations but is statistically significant in only 9 out of the 19 models, and not always for all ensemble members. The distribution of these trends is presented in Table 1 (last column; it can also be gleaned from the x-coordinates of the dots in the scatter plot in Fig. 9, to be discussed shortly). One can see that this upward trend varies widely in magnitude, from 0.4 to 1.9 (where significant), in units of standard deviation of the observed SNAO index per century, with a mean value, across all models, of 0.4 (since all data are on an equal grid, the amplitudes of the PC trends can be compared). The upper estimate for the projected SNAO trend is about 5 times larger than the weak and non-significant trend observed for the period 1950-2010 but comparable to the strong trend that was observed until 2000 and that is best interpreted as a multi-decadal fluctuation (see discussion in B2011 and below). Corresponding projected SLP increases over the UK, linearly related to this SNAO trend, range from 1 to $5 \mathrm{hPa}$ per century, with the highest estimate being again comparable to the strong JA SLP increase that was observed from 1950 to 2000 in this region [Hurrell and Folland, 2002].

Given the strong influence of the SNAO on precipitation in NW Europe, we anticipate that this SNAO trend, when present in a model, will greatly impact the projected precipitation change in this region. To assess this influence, we first compare the multi-model mean projected change (Fig. 1) with the corresponding expected change due to SNAO trend (Fig. 8). That is, for each simulation, we multiply the projected 2010-2099 SNAO trend by the detrended regression of 
precipitation onto the SNAO index (for the 1950-2010 baseline period) and then compute the multi-model ensemble-mean, as usual. On average, the upward trend in the SNAO contributes between $40 \%$ and $120 \%$ of the mean projected drying in the UK, northwest Europe and southern Scandinavia. However, we also expect this contribution to vary considerably from model to model and lead to large variations in the magnitude of the projected drying. This is confirmed by a scatter plot between the future SNAO trend and the regional-mean precipitation trend across individual CMIP3 simulations (Fig. 9a). The box chosen here encompasses only the portion of the NWE region in which the multi-model ensemble projects a decrease in precipitation in the $21^{\text {st }}$ century (i.e., the northern limit is $58.5^{\circ} \mathrm{N}$ rather than $65^{\circ} \mathrm{N}$; see box NWE-2 in Fig. 1), $50 \%$ of which being accounted for by the SNAO trend (Fig. 8). The simulations with the strongest positive SNAO trends (GFDL-CM2.0 and 2.1, HadCM3 and ECHAM5) indeed project pronounced drying in this region, whereas the simulations with weak SNAO trends project little precipitation change (the few models that project a negative SNAO trend predict weak increases in precipitation. See Fig. S4 for individual trend maps for each model).

Thus, although drying not related to the SNAO also occurs in this region and must vary from one model to another, the spread in the SNAO trend alone accounts for a very large fraction $(64 \%, r=-0.8)$ of the inter-model spread in the magnitude of the drying. In other words, much of the uncertainty in the projected precipitation change in this region is attributable to uncertainties in the future change in the SNAO. This is similar to the relationship that has been found in winter between the intensity of the projected CMIP3 trend in the northern anular mode (NAM) and drying in Iberia [Karpechko, 2010], although the inter-model spread in the NAM trend only accounts for $38 \%$ of the spread in the drying and the future winter SLP change projects less clearly onto the NAM (e.g., [Osborn, 2011]). Our finding is consistent with the results in Boé et al. [2009], who report a correlation of -0.85 between the increase in the frequency of occurrence of daily positive SNAO regimes and the decrease in mean precipitation over the UK in a subset of 15 CMIP3 simulations. It should be pointed out, however, that a recent study [van Haren et al, 2012] 
has compared CMIP3 simulated trends with observations in the NWE-2 region and found a coastal wetting trend in the last century during summer that is not reproduced by the models, which casts doubt on the reliability of the projections.

Also shown in Fig. 9a is the slope of the observed regression between the SNAO index and precipitation anomalies (dashed line) and the observed precipitation and SNAO linear trends for both the $1950-2000$ and the $1950-2010$ periods (asterisks connected by a dotted line) - recall the strong SNAO trend that was observed during the former period. These observational estimates can be compared with the linear fit between CMIP3 projected precipitation and SNAO trends (solid line). The two observational lines are consistent with each other (i.e., their slopes are similar) and confirm that the positive SNAO swing that occurred between 1965 and 2000 made a large contribution to the concurrent drying that was observed in NW Europe [Hurrell and Folland, 2002; Baines and Folland, 2007; B2011]. The magnitude of the simulated projected changes in precipitation relative to the SNAO trend appears in line with the recent observed changes (asterisks), in as much as these lie within the range of the simulated estimates, but the projected precipitation decrease in response to a given SNAO trend seems somewhat stronger in the models (i.e., the solid line is steeper). We have verified, however, that if the two outlier models (HadCM3 and GFDL-CM2.1) are not taken into account, the trends across models lie on a curve with nearly the same slope as the observations (Fig. S3a), in line with the fact that the magnitude of the simulated regressions between the SNAO and precipitation in this region is similar, overall, to the observed value (not shown but recall the correlations in Fig. 5).

In contrast with the NWE region, over the eastern Mediterranean, because the simulated precipitation is only weakly influenced by the SNAO, the relationship between future SNAO and precipitation trends is inconsistent with what would be anticipated based on the strong observed correlation on interannual time-scales; that is, a partial compensation of the drying external to the SNAO when the SNAO trend is strong and a positive correlation between projected SNAO and precipitation trends. Instead the simulated correlation is negative (Fig. 9b). One should note, 
however, that no significant increase in precipitation occurred during the 1950-2000 period in this region (see red asterisk in Fig. 9b), despite the presence of a strong SNAO trend, as discussed in B2011. Yet, the trends are parallel (and significant) until 1985, before temperatures in this region started to rise (not shown). This may indicate that other factors in recent decades have been operating and off-setting the SNAO influence, such as soil-moisture feedbacks triggered by the pronounced warming that has occurred since the 1980s, or perhaps aerosol effects.

Even so, one would expect that, if the models simulated the relationship between the SNAO and precipitation realistically, those with the strongest future SNAO trends would tend to project weaker drying in the Balkans/Italy. This is clearly not the case (Fig. 9b). In fact, paradoxically, in the two GFDL models, the strong positive SNAO trends are apparently associated with increased drying in this region. It turns out, however, that this enhanced drying is not linearly congruent with the SNAO, i.e., the two time series simply share a strong trend, as demonstrated by the fact that the linear relationship between the future precipitation and SNAO time series does not hold when the time series are detrended. When these two models are removed, the correlation between future changes in the SNAO and precipitation in the Balkan/Italy region becomes non-significant $(-0.14$, Fig. S3b), as expected from the weak and inconsistent simulated correlations/regressions between the SNAO and precipitation (Fig. 5-6).

\section{6) Summary and discussion}

In this study we have resumed the comparison between the observed and simulated summer NAO begun in B2011 and extended it to the rest of the CMIP3 models. We have shown that most models can reproduce the spatial SLP signature and the broad-scale dipolar precipitation impact of the SNAO in the Euro-Mediterranean region, particularly the strong drying in NW Europe that occurs during positive SNAO summers. The concurrent observed wet conditions in southern Europe, however, are systematically weak in the eastern Mediterranean, where the observed signal is most pronounced (although several models perform better than the two singled 
out in B2011). Our results also confirm the findings in B2011 that the failure of the models to correctly capture the precipitation response to the SNAO in the eastern Mediterranean is related to their inability to accurately reproduce the observed trough that develops at upper levels in this region and creates potential instability. This trough is consistently too weak in the models and/or shifted from its observed position.

Because of the strong (and correctly simulated) impact of the SNAO in NW Europe, any long-term change in the SNAO will result in substantial precipitation changes, in observations as well as in the models. The future SNAO trend is generally projected to be positive and indeed accounts for a large fraction of the reduction in precipitation predicted by the multi-model mean ensemble in this region (50\%). However, the strength of the SNAO trend varies greatly across models and this spread then leads to a very large uncertainty in the magnitude of the projected drying in northwest Europe (64\% of the spread in the drying is due to the spread in the SNAO trend). Moreover, because of their unrealistically weak SNAO impact in the eastern Mediterranean, the models fail to simulate the relative enhancement of precipitation that should accompany an upward SNAO trend in this region and partly compensate for the drying due to other processes (presumably soil moisture feedbacks). It should be noted that this Mediterranean drying feeds back on the circulation in central Europe via the heat low that develops in the Mediterranean area, bringing dry easterly winds into central Europe and greatly contributing to the projected drying in this region [Haarsma et al., 2009]. Thus, the model biases due to the missing SNAO teleconnection (which, if present, would act to weaken the heat low) may extend to a larger area than the Italy/Balkan region and lead to excessive projected drying over central Europe also.

In assessing the importance of these model shortcomings for projections of future climate change, we are hampered by the fact that, currently, no theoretical framework exists for the sensitivity of the SNAO to external forcing, so it is unclear whether the response of the SNAO to increased greenhouse gases and aerosols will indeed take the form of an upward trend. Additionally, as discussed in B2011, it is also uncertain whether the behavior of the SNAO in the past and, 
especially, in recent years has been influenced by anthropogenic forcing. This is because the observational record is ambiguous: the low-frequency evolution of the SNAO is dominated by variations on multi-decadal time-scales, with long-term (1899-2010) and short-term (1950-2010) trends that, although weakly positive, are not statistically significant. On the other hand, tree-ring proxy data provide some suggestion of a slow upward long-term trend in the SNAO extending back to 1706 [F2009].

One complicating factor is that the SNAO may respond to other slow forcings in addition to anthropogenic forcing or the anthropogenic signal may involve a combination of mechanisms. For instance, Balmaseda et al. [2010] show that, in the ECMWF model, the atmospheric response to the recent reduction in Arctic sea-ice bears some resemblance to the negative phase of the SNAO (when the SST is also prescribed). Likewise, a negative correlation between an observed low-pass filtered AMO index and the SNAO has been reported in F2009, a result that is replicated in some models [Knight et al., 2006] but not others (e.g., the ECHAM5 ensemble described in van Oldenborgh et al., 2009). Although the evidence at this point is mixed, both processes could complicate detection of a possible anthropogenic trend.

With regards to the variation of the projected SNAO trend across models, the existence of a significant upward trend, or lack thereof, does not appear to be related to the skill of the model in reproducing the observed SNAO pattern (cross-reference columns 6 and 8 with 16), so this performance cannot be used as a metric to give credence to some projections over others. On the other hand, it is suggestive that all models with pronounced positive SNAO trends have relatively coarse resolution $\left(2.5^{\circ} \times 2.75^{\circ}\right.$, or lower, see Table 1$)$, whereas the higher resolution MIROC $3.2 \mathrm{~h}$ and ECHAM4 models $\left(1.1^{\circ} \times 1.1^{\circ}\right)$ have non-significant trends. Confirmation of this result and attribution of the SNAO trend (whether or not related to model resolution) needs to await completion of the new suite of higher-resolution CMIP5 experiments. Note that, even if the externally-forced SNAO trend turns out to be small in those simulations, understanding the causes of long-term multi-decadal variations in the SNAO becomes important for decadal climate prediction in the Euro-Mediterranean 
region, given the strong influence of the SNAO on decadal timescales [F2009; Mariotti and Dell'Aquila, 2011].

Because the observed upper level-trough that is instrumental in producing an SNAO Mediterranean signature appears to be part of a circumglobal wavetrain (B2011), we speculate that the models' misrepresentation of this trough is related to deficiencies in the simulation of the North African summer jet and associated Rossby wave guide. The error may be aggravated by the fact that summer precipitation in this region is usually associated with mesoscale events and strongly influenced by orography, neither of which is well captured by current GCMs. Investigation of the role of the summer jet in the development of the SNAO Mediterranean teleconnection is also left for a later study with the new and presumably improved CMIP5 models. Future work will also include diagnostics of the potential instability induced by the SNAO in the Mediterranean region, as was done for observations in B2011.

As a technical point, we note that the two GFDL models exhibit outlier behavior in several regards. They project the most dramatic upward SNAO trend (only matched by the HadCM3 model), they exhibit the largest precipitation response to the presence of a $200-\mathrm{hPa}$ trough in the Balkans and they also project pronounced drying in the Balkans, unrelated to the SNAO trend. Again, we plan to revisit these peculiarities in the context of the improved CMIP5 ensemble.

Most scenario efforts are based on the assumption that the CMIP ensemble is an unbiased estimate of the future climate and its uncertainty. While it is generally recognized that the models are not truly independent - because of pragmatic/historical reasons and because of structural uncertainties [e.g., Knutti et al., 2010; Stainforth et al., 2007] - and so the implied uncertainties are too low, it should be kept in mind that this commonality across models may also lead to systematic biases (e.g., the well-known double ITCZ problem). These may result from common errors in the simulation of certain fundamental aspects of the general circulation or the seasonal cycle. This paper shows yet another area, the Balkan/Italy region, in which the models have a common bias and 
thus the CMIP3 ensemble cannot be used as a basis for future climate scenarios. This bias may also affect a wider region through the intensification of the Mediterranean heat low projected by most models.

\section{Acknowledgements:}

We are grateful to Pablo Zurita for his useful comments on the manuscript. We also thank Chris Folland and two anonymous reviewers for their constructive suggestions for improvement of the manuscript. DF was supported by grant CONSOLIDER 2007-CSD2007-00050. The work was funded by grant DEVIAJE CGL2009-06944, of the Spanish MICINN. We acknowledge the modeling groups, the Program for Climate Model Diagnosis and Intercomparison (PCMDI) and the WCRP's Working Group on Coupled Modelling (WGCM) for their roles in making available the WCRP CMIP3 multi-model dataset.

\section{References:}

- Baines, P.G. and C. K. Folland (2007), Evidence for a rapid global climate shift across the late 1960s, J. Climate, 20, 2721-2744, doi:10.1175/JCL14177.1.

- Balmaseda, M. A., L. Ferranti, F. Molteni and T. N. Palmer (2010), Impact of 2007 and 2008 Arctic ice anomalies on the atmospheric circulation: Implications for long-range predictions, Quarterly J. Royal Met. Soc., 136, 1655-1664.

- Bladé I., B. Liebmann, D. Fortuny, G. J. Oldenborgh (2011), Observed and simulated impacts of the summer NAO in Europe: implications for projected drying in the Mediterranean region, Climate Dynamics. DOI: 10.1007/s00382-011-1195-x

- Boé, J., L. Terray, C. Cassou, and J. Najac (2009), Uncertainties in European summer precipitation changes: role of large scale circulation, Clim. Dyn. 33, 265-276.

- Chen, M., P. Xie, J. E. Janowiak, and P. A. Arkin (2002), Global Land Precipitation: A 50-yr Monthly Analysis Based on Gauge Observations, J. of Hydrometeorology, 3, 249-266

- Chen, M., P. Xie, J.E. Janowiak, and P.A. Arkin (2004), Verifying the reanalysis and climate models outputs using a 56-year data set of reconstructed global precipitation, 14th AMS Conf. 
Appl. Meteor., 11-15 January, 2004, Seattle, WA.

- Chronis, T., D. E. Raitsos, D. Kassis and A. Sarantopoulos (2011), The summer North Atlantic Oscillation influence on the eastern Mediterranean, J. Climate, 24, 5584-5596.

- Faller, A. J. (1981): An average correlation coefficient, Journal of Applied Meteorology, vol. 20, pp. 203-5.

- Folland, C. K., J. Knight, H. W. Linderholm, D. Fereday, S. Ineson, and J. W. Hurrell (2009), The Summer North Atlantic Oscillation: Past, Present, and Future, J. Climate, 22, 1082-1103. DOI: $10.1175 / 2008 J C L I 2459.1$.

- Greatbatch, R. J., and P.-P. Rong (2006), Discrepancies between Different Northern Hemisphere Summer Atmospheric Data Products, J. Climate, 19, 1261-1273.

- Giorgi F. and E. Coppola (2007), The European Climate-Change Oscillation (ECO), Geophys. Res. Lett., 34, L217003, doi: 10.1029/2007GL031223

- Haarsma, R. J., F. M. Seoten, B. J. J. M. van den Hurk, W. Hazeleger and X. Wang (2009), Dry Mediterranean Soils due to Greenhouse Warming bring easterly Winds over Summertime Central Europe, Geophys. Res. Lett, 36, L04705. DOI:10.1029/2008GL036617.

- van Haren, R., G. J. van Oldenborgh, G. Lenderink, M. Collins and W. Hazeleger (2012), SST and circulation trend biases cause an underestimation of European precipitation trends, Clim.Dyn., $10.1007 / \mathrm{s} 00382-012-1401-5$.

- Held, I. M. and B. J. Soden (2006), Robust responses of the hydrological cycle to global warming, Journal of Climate, 19 (21), 5686-5699.

- Hurrell, J. W., and C. K. Folland (2002), A change in the summer circulation over the North Atlantic, CLIVAR Exchanges, No. 25, International CLIVAR Project Office, Southampton, United Kingdom, 52-54.

- Janowiak, P. A. Arkin, and T. M. Smith (2003), Reconstruction of the oceanic precipitation from 1948 to the present, Proceedings of the $14^{\text {th }}$ AMS Symposium on Global Change and Climate Variations, Long Beach, CA, 2003. 
- Karpechko, A. Y. (2010), Uncertainties in future climate attributable to uncertainties in future Northern Annular Mode trend, Geophys. Res. Lett., 37, L20702, doi:10.1029/2010GL044717.

- Knight, J. R., C. K. Folland, and A. A. Scaife (2006), Climate impacts of the Atlantic Multidecadal Oscillation, Geophys. Res. Lett., 33, L17706, doi:10.1029/2006GL026242.

- Knutti, R., R. Furrer, C. Tebaldi, J. Cermak and G.A. Meehl (2010), Challenges in combining projections from multiple models, J. Climate, 23, 2739-2758, doi:10.1175/2009JCLI3361.1.

- Lu, J., G. A. Vecchi, and T. Reichler (2007), Expansion of the Hadley cell under global warming, Geophys. Res. Lett., 34, L06805, DOI:10.1029/2006GL028443.

- Mariotti A., and P. Arkin (2007), The North Atlantic Oscillation and oceanic precipitation variability, Climate Dynamics, Volume 28 (1), 35-51.

- Mariotti A., and A. Dell'Aquila (2011), Decadal climate variability in the Mediterranean region: roles of large-scale forcings and regional processes, Climate Dynamics, 38, 1129-1145. doi:10.1007/s00382-011-1056-7.

- Meehl, G. A., and Coauthors (2007), Global climate projections. Climate Change 2007: The Physical Science Basis, S. Solomon et al., Eds., Cambridge University Press, 747-845.

- North, G. R., T. L. Bell, R. F. Cahalan, and F. J. Moeng (1982), Sampling errors in the estimation of empirical orthogonal functions, Mon. Wea. Rev., 110, 699-706.

- Osborn, T.J. (2011), Variability and changes in the North Atlantic Oscillation index. In Hydrological, socioeconomic and ecological impacts of the North Atlantic Oscillation in the Mediterranean region (eds. Vicente-Serrano SM and Trigo RM), Springer Dordrecht, Heidelberg, 9-22, (doi:10.1007/978-94-007-1372-7).

- Osborn, T.J. (2004), Simulating the winter North Atlantic Oscillation: the roles of internal variability and greenhouse gas forcing, Climate Dynamics 22, 605-623 (doi:10.1007/s00382-0040405-1).

- Ossó, A., Y. Sola, J. Bech, and J. Lorente (2011), Evidence for the influence of the North Atlantic Oscillation on the total ozone column at northern low latitudes and midlatitudes during 
winter and summer seasons, J. Geophys. Res., 116, D24122, doi:10.1029/2011JD016539

- Rodwell M. J., and B. J. Hoskins (1996), Monsoons and the dynamics of deserts, Quart. J. Roy. Meteor. Soc., 122, 1385-1404.

- Rowell, D. P., and R. G. Jones (2006), Causes and uncertainty of future summer drying over Europe, Climate Dyn., 27, 281-299. doi:10.1007/s00382-006-0125-9.

- Scheff, J., and D. M. W. Frierson (2012), 21st-century multi-model subtropical precipitation declines are mostly mid-latitude shifts. In press, J. Climate. 10.1175/JCLI-D-1100393.110.1175/JCLI-D-11-00393.1

- Shin, S.-I. and P. D. Sardeshmukh (2011), Critical influence of the pattern of Tropical Ocean warming on remote climate trends, Clim. Dyn., 36, 1577-1591, doi: 10.1007/s00382-009-0732-3.

- Stainforth, D. A., Allen, M. R., Tredger, E. R. \& Smith, L. A. (2007), Confidence, uncertainty and decision-support relevance in climate predictions, Philosophical Transactions of the Royal Society A, 365, 2145-2161. DOI: 10.1098/rsta.2007.2074

- Taylor, K. E. (2001), Summarizing multiple aspects of model performance in a single diagram, J. Geophys. Res., 106(D7), 7183-7192, doi:10.1029/2000JD900719.- Trenberth, K. E., and D. A. Paolino Jr. (1980), The Northern Hemisphere sea-level pressure data set: Trends, errors and discontinuities, Mon. Wea. Rev., 108, 855-872.

- van Oldenborgh, G. J., L. A. Te Raa, H. A. Dijkstra and S. Y. Philip (2009), Frequency- or amplitude-dependent effects of the Atlantic meridional overturning on the tropical Pacific Ocean, Ocean Science, 5, 293-301. 10.5194/os-5-293-2009

- Van Ulden, A. P. and G. J. van Oldenborgh (2006), Large-scale atmospheric circulation biases and changes in global climate model simulations and their importance for climate change in Central Europe, Atmos. Chem. Phys. 6, 863-881. 10.5194/acp-6-863-2006.

- Wilks, D. S. (2006), Statistical Methods in the Atmospheric Sciences, 2nd ed. Academic Press, $467 \mathrm{pp}$.

- Ziv, B., H. Saaroni, and P. Alpert (2004), The factors governing the summer regime of the 
eastern Mediterranean, Int. J. Climatol., 24, 1859-1871.

\section{Figure captions:}

Figure 1. The 2010-2099 CMIP3 multi-model summer (July-August) precipitation trend in $\mathrm{mm} /$ day/century. The 19 models and 44 simulations used are listed in Table 1 (the rationale for which models were discarded is discussed in section 3). Data were interpolated to a common $0.5^{\circ}$ $\mathrm{x} 0.5^{\circ}$ grid. The trends here and in other figures are computed as linear regressions. For each model, all available ensemble members have been averaged and the multi-model mean has been computed. The four boxes indicate the regions where areal averages are computed throughout the paper: northwest Europe (NWE), the smaller region in northwest Europe in which the multi-model precipitation trend is negative (NWE-2), the southeast Europe/Mediterranean (SEM) and the Balkan-Italy region (BAL-ITA).

Figure 2. Taylor-like diagram comparison of observed and simulated summer NAO (SNAO) for the period 1950-2010. The observed SNAO is the leading EOF of July-August mean SLP in the domain $\left(40^{\circ} \mathrm{N}-70^{\circ} \mathrm{N} ; 90^{\circ} \mathrm{W}-30^{\circ} \mathrm{E}\right)$ and is shown in the inset, where it is displayed in terms of the regression between the detrended normalized PC time series and SLP at every grid-point (the box shows the domain in which the EOF is computed). Thus, the anomalies correspond to a standard deviation of the SNAO time series. Contour is $0.5 \mathrm{hPa}$. Each dot in the Taylor diagram represents the pattern anomaly correlation $r_{s}$ (angular coordinate) and rms magnitude ratio $A$ (radial coordinate) between the simulated leading EOF that most resembles the SNAO in each CMIP3 simulation (either EOF1 or EOF2) and the observed SNAO. Model names are indicated on the right together with the number of ensemble members used (simulations in which the corresponding EOF was not well separated from the next are omitted). The bottom left (right) panel shows the simulated SNAO in the CSIRO-MK35 (IPSL-CM.4) models, which exhibit a very high (low) spatial anomaly correlation with the observed pattern.

Figure 3. Left panel: The observed SNAO time series correlated against mean July-August SLP 
(top), precipitation (middle) and 200-hPa geopotential height (bottom), for the period 1950-2010. Shading interval is 0.1 in all panels but with the first contours omitted for SLP and geopotential height. Right panel: same for the multi-model mean. For each simulation an SNAO time series (or pseudo-PC) is obtained by projecting the observed SNAO pattern onto the model SLP field. The resulting one-point correlation maps are averaged using the Fisher's Z transform (see text for more details). Data have been interpolated to a common grid: $2.5^{\circ} \times 2.5^{\circ}$ for SLP and geopotential height and $0.5^{\circ} \times 0.5^{\circ}$ for precipitation (see section 2 for more details).

Figure 4. Left box: Model correlations of July-August mean SLP (top), precipitation (middle) and 200-hPa geopotential height (bottom) with the corresponding SNAO pseudo-PC, averaged over the nine simulations with the weakest (left) and strongest (right) precipitation response in NW Europe (see NWE box in middle panels). See text for more details. Contour interval is the same as in Figure 3. Right box: same but for the southeast Europe/Mediterranean (see SEM box in middle panels). Analysis period is $1950-2010$.

Figure 5. Correlation between the SNAO index and mean precipitation in the NWE region (bottom portion of plot, below thick blue line) and Balkan-Italy (BAL-ITA) region (top, above thick blue line) in each CMIP3 simulation. The dotted lines indicate the corresponding observed correlation; the grey shading indicates the $95 \%$ confidence limits according to a non-parametric bootstrap test. The two models examined in B2011 are shaded in light green.

Figure 6. a) Scatter plot of the regression of precipitation onto the SNAO index, averaged over the Italy/Balkan region (x-axis), versus the regression of precipitation onto 200-hPa heights (also averaged over the same region), for all individual CMIP3 simulations. That is, the $y$-axis is the strength of the mean precipitation response to a one meter $200-\mathrm{hPa}$ geopotential height mean anomaly in this region (in $\mathrm{mm} / \mathrm{day} / \mathrm{m}$ ). Regressions onto the SNAO index are expressed in terms of anomaly ( $\mathrm{mm} /$ day) per unit deviation of the projected SNAO index, where a unit corresponds to the standard deviation of the observed (detrended) SNAO index. The observational value is shown 
with a black asterisk. The linear correlation with $95 \%$ confidence intervals, computed using a nonparametric bootstrap test, and the correlation without the GFDL models (outliers) are indicated in the lower left. Model symbols are indicated at the bottom. b) Same but the y-axis is the regression of area-averaged 200-hPa geopotential height onto the SNAO index (in m).

Figure 7. Multi-model mean of July-August mean SLP differences between the second half of the $21^{\text {st }}$ century and the second half of the $20^{\text {th }}$ century. Contour is $0.25 \mathrm{hPa}$.

Figure 8. Multi-model mean expected precipitation trend for the 2010-2099 period in $\mathrm{mm} /$ day/century due to the influence of the SNAO, based on the detrended regression of precipitation onto the SNAO (for the 1950-2010 baseline period) and the projected SNAO trend. The red lines and the grey hatching indicate the percent contribution to the total precipitation trend accounted for by the SNAO, in increments of $20 \%$, starting at $20 \%$ (southernmost line). Hatching is applied only when the total trend exceeds $0.1 \mathrm{~mm} /$ day/century (see Fig. 1). The box is the NWE-2 box discussed in the text (the mean contribution of the SNAO to the drying trend in this region is $50 \%$ ).

Figure 9. a) Scatter plot of projected JA precipitation linear trends in the NWE-2 box (see Fig. 8), in $\mathrm{mm} /$ day/century, versus projected SNAO trend (in units of detrended standard deviation of the observed SNAO index per century) for the 2010-2099 period. Model symbols are indicated at the bottom. SNAO trends that exceed the two-tailed 95\% significance level according to a Monte Carlo test are indicated with a bigger symbol (see also Table I). The solid line indicates a linear fit calculated using all simulations (the correlation coefficient with $95 \%$ confidence intervals, computed using a non-parametric bootstrap test, and the correlation without the GFDL-CM2.1 and HADCM3 outlier models is indicated in the lower left. See also Fig. S3a). The black (red) asterisk indicates the observed SNAO and precipitation trend for the period 1950-2010 (19502000). The dotted line indicates future precipitation trends estimated by using these recent observed trends, while the dashed line shows the linear change in precipitation expected for a 
given SNAO trend based on the observed (detrended) regression between the SNAO index and mean precipitation anomalies in this region. b) Same for the Balkan-Italy region. In this case the outliers are the two GFDL models (see Fig. S3b). The recent precipitation trends (asterisks) are both weak and not statistically significant and thus cannot be used as an estimate of future precipitation trends associated with the SNAO.

\section{Table 1. A complete description of the summer NAO (SNAO) characteristics in the CMIP3} simulations used in this study.

All simulations are spliced 20C3M/SRESA1B runs for the period 1900-2099 and have been interpolated to a common grid (see section 2). All but the last column refer to the period 19502010. The first, second and third columns indicate the model name, original resolution and run number. The fourth and fifth columns show the variance explained by EOF-1 and EOF-2 of SLP (sea level pressure) in the SNAO domain (see text). The variance explained by EOF-2 is only shown when this mode, not EOF-1, is the mode that most resembles the SNAO (this is also indicated by the bold print). When an EOF is not well-separated from the next, the variance is depicted in italics. The sixth and eight columns show the values in the Taylor diagram of Fig. 2: the spatial anomaly correlation of the simulated SNAO with the SNAO baseline pattern $\left(r_{s}\right)$ and the ratio of their rms amplitudes $(A)$. The ensemble-mean spatial anomaly correlation is shown in the seventh column. The next three columns refer to the model "pseudo" SNAO obtained by projecting the observed SNAO onto the models' SLP field: the percent of explained variance is shown in column 9, the temporal correlation between the SNAO principal component (PC) and the pseudo-PC is shown in column 10 while the spatial anomaly correlation between the observed SNAO and the projected SNAO is shown in column 11. Good agreement with the SNAO $\left(r_{s}>0.9\right)$ is high-lighted in bold print (also in columns 6-7). The next two columns show the values plotted in Figure 5, i.e., the correlation between the (pseudo) SNAO index and mean precipitation in the northwest Europe (NWE) box (column 12) and the Balkan/Italy box (column 13). The next two 
columns show the values used to construct Fig. 4, i.e. the area-mean correlation between the SNAO index and precipitation in the NWE box (column 14) and the southeast Mediterranean (SEM) box (column 15). The nine simulations chosen for the high-end/low-end STRONG and WEAK response plots are highlighted in light grey and dark grey, respectively. The final column (16) shows the values of the trend in the SNAO (pseudo-PC) for the period 2010-2099, or xcoordinates of the dots in Figure 9 (statistical significance at the 95\% level is indicated in bold). The grey rows correspond to the simulations eventually discarded and not included in Figs. 3-9, based on the low spatial anomaly correlation between the projected SNAO and the observed SNAO $\left(r_{s}<0.8\right.$, column 11) or because of missing data.

The first row corresponds to the observed SNAO and therefore only includes some of the quantities.

\begin{tabular}{|c|c|c|c|c|c|c|c|c|c|c|c|c|c|c|c|}
\hline MODEL & resolution & $\begin{array}{c}\text { run } \\
\#\end{array}$ & $\begin{array}{l}\text { var. } \\
\text { EOF1 }\end{array}$ & $\begin{array}{l}\text { var. } \\
\text { EOF2 }\end{array}$ & $\begin{array}{l}\text { ASC } \\
\left(r_{s}\right)\end{array}$ & $\begin{array}{c}\text { ens- } \\
\text { mean } \\
\text { ASC }\end{array}$ & $\begin{array}{c}\text { RMS } \\
\text { (A) }\end{array}$ & $\begin{array}{c}\text { var. } \\
\text { pseudo } \\
\text { PC }\end{array}$ & $\begin{array}{c}\text { cor. } \\
\text { PC/ } \\
\text { pseud } \\
\text { PC }\end{array}$ & $\begin{array}{c}\text { ASC } \\
\text { proj } \\
\text { SNAO } \\
\text { /obs }\end{array}$ & $\begin{array}{c}\text { cor. } \\
\text { SNAO } \\
\text { /mean } \\
\text { NWE } \\
\text { prec }\end{array}$ & $\begin{array}{c}\text { cor. } \\
\text { SNAO } \\
\text { /mean } \\
\text { BAL-IT } \\
\text { prec }\end{array}$ & $\begin{array}{c}\text { mean } \\
\text { cor. } \\
\text { SNAO } \\
\text { /NWE } \\
\text { prec }\end{array}$ & $\begin{array}{c}\text { mean } \\
\text { cor. } \\
\text { SNAO } \\
\text { /SEM } \\
\text { prec }\end{array}$ & $\begin{array}{l}\text { SNAO } \\
\text { trend } \\
2010- \\
2099\end{array}$ \\
\hline observations & $2.5^{\circ} \times 2.5^{\circ}$ & & $35.0 \%$ & & & & & & & & -0.86 & 0.65 & -0.67 & 0.41 & \\
\hline bccrbcm 20 & $1.9^{\circ} \times 1.9^{\circ}$ & 01 & $48.1 \%$ & & 0.68 & 0.68 & 1.13 & $31.5 \%$ & 0.71 & 0.82 & -0.54 & 0.20 & -0.31 & 0.07 & 0.60 \\
\hline \multirow{6}{*}{$\operatorname{ccsm} 3$} & \multirow{6}{*}{$1.4^{\circ} \times 1.4^{\circ}$} & 01 & $36.9 \%$ & & 0.93 & \multirow{6}{*}{0.90} & 1.30 & $35.6 \%$ & 0.96 & 0.96 & -0.87 & 0.31 & -0.59 & 0.11 & 0.61 \\
\hline & & 02 & $36.2 \%$ & & 0.90 & & 1.27 & $33.9 \%$ & 0.94 & 0.94 & -0.82 & 0.09 & -0.54 & 0.05 & -0.30 \\
\hline & & 03 & $38.7 \%$ & & 0.85 & & 1.31 & $35.7 \%$ & 0.94 & 0.92 & -0.86 & 0.22 & -0.48 & 0.05 & 0.00 \\
\hline & & 05 & $36.1 \%$ & & 0.87 & & 1.19 & $34.8 \%$ & 0.98 & 0.92 & -0.87 & 0.31 & -0.59 & 0.14 & 0.36 \\
\hline & & 06 & $35.4 \%$ & & 0.89 & & 1.26 & $32.0 \%$ & 0.90 & 0.95 & -0.76 & 0.44 & -0.48 & 0.20 & 0.11 \\
\hline & & 07 & $43.9 \%$ & & 0.88 & & 1.40 & $40.7 \%$ & 0.94 & 0.94 & -0.85 & 0.33 & -0.62 & 0.11 & 0.49 \\
\hline \multirow{5}{*}{ cgcm31t47 } & \multirow{5}{*}{$\sim 2.8^{\circ} \times 2.8^{\circ}$} & 01 & $37.6 \%$ & & 0.83 & \multirow{5}{*}{0.75} & 1.15 & $33.7 \%$ & 0.91 & 0.92 & -0.82 & 0.19 & -0.51 & 0.08 & 0.77 \\
\hline & & 02 & $33.9 \%$ & & 0.73 & & 1.03 & $27.9 \%$ & 0.78 & 0.91 & -0.76 & 0.25 & -0.41 & 0.18 & 0.77 \\
\hline & & 03 & $29.4 \%$ & & 0.53 & & 0.96 & $22.7 \%$ & 0.56 & 0.86 & -0.72 & 0.01 & -0.37 & -0.02 & 0.40 \\
\hline & & 04 & $35.9 \%$ & & 0.82 & & 1.04 & $33.0 \%$ & 0.94 & 0.91 & -0.70 & 0.19 & -0.38 & 0.06 & 0.11 \\
\hline & & 05 & $33.5 \%$ & & 0.75 & & 1.05 & $29.4 \%$ & 0.85 & 0.92 & -0.73 & 0.15 & -0.41 & -0.01 & -0.39 \\
\hline cgcm31t63 & $\sim 1.9^{\circ} \times 1.9^{\circ}$ & 01 & $35.5 \%$ & & 0.84 & 0.84 & 1.11 & $31.9 \%$ & 0.90 & 0.94 & -0.71 & 0.43 & -0.39 & 0.20 & -0.16 \\
\hline cnrmcm3 & $\sim 1.9^{\circ} \times 1.9^{\circ}$ & 01 & $38.7 \%$ & $22.9 \%$ & 0.75 & 0.75 & 0.65 & $21.6 \%$ & 0.92 & 0.89 & -0.51 & 0.31 & -0.27 & 0.18 & 0.46 \\
\hline csiromk30 & $\sim 1.9^{\circ} \times 1.9^{\circ}$ & 01 & $38.6 \%$ & & 0.69 & 0.69 & 1.16 & $31.0 \%$ & 0.75 & 0.92 & -0.84 & 0.50 & -0.49 & 0.29 & 0.00 \\
\hline csiromk35 & $\sim 1.9^{\circ} \times 1.9^{\circ}$ & 01 & $36.0 \%$ & & 0.94 & 0.94 & 1.06 & $35.7 \%$ & 0.99 & 0.95 & -0.82 & 0.18 & -0.47 & 0.04 & 0.05 \\
\hline echam4 & $\sim 1.1^{\circ} \times 1.1^{\circ}$ & 01 & $25.1 \%$ & & 0.79 & 0.79 & 0.75 & $24.2 \%$ & 0.87 & 0.95 & -0.80 & 0.51 & -0.47 & 0.23 & 0.33 \\
\hline \multirow{4}{*}{ echam5 } & \multirow{4}{*}{$\sim 1.9^{\circ} \times 1.9^{\circ}$} & 01 & $29.5 \%$ & & 0.94 & \multirow{4}{*}{0.92} & 1.01 & $29.0 \%$ & 0.99 & 0.96 & -0.77 & 0.29 & -0.45 & 0.11 & 0.90 \\
\hline & & 02 & $37.8 \%$ & & 0.81 & & 1.21 & $33.0 \%$ & 0.85 & 0.93 & -0.70 & 0.44 & -0.41 & 0.20 & 0.77 \\
\hline & & 03 & $34.8 \%$ & & 0.82 & & 1.10 & $29.3 \%$ & 0.82 & 0.93 & -0.68 & 0.47 & -0.39 & 0.18 & 0.18 \\
\hline & & 04 & $31.4 \%$ & $21.3 \%$ & 0.88 & & 0.86 & $21.7 \%$ & 0.91 & 0.97 & -0.81 & 0.39 & -0.44 & 0.19 & 0.00 \\
\hline \multirow{2}{*}{ echog } & \multirow{2}{*}{$\sim 3.9^{\circ} \times 3.9^{\circ}$} & 01 & $37.5 \%$ & & 0.53 & \multirow{2}{*}{0.52} & 1.12 & $28.0 \%$ & 0.78 & 0.77 & & & & & \\
\hline & & 02 & $32.4 \%$ & & 0.50 & & 1.07 & $24.3 \%$ & 0.73 & 0.87 & & & & & \\
\hline \multirow{3}{*}{ fgoalsg10 } & \multirow{3}{*}{$\sim 2.8^{\circ} \times 2.8^{\circ}$} & 01 & $38.5 \%$ & & 0.60 & \multirow{3}{*}{0.57} & 0.9 & $23.8 \%$ & 0.65 & 0.75 & & & & & \\
\hline & & 02 & $47.4 \%$ & & 0.52 & & 1.10 & $32.0 \%$ & 0.75 & 0.64 & & & & & \\
\hline & & 03 & $44.2 \%$ & & 0.57 & & 1.04 & $28.8 \%$ & 0.68 & 0.71 & & & & & \\
\hline gfdlcm 20 & $2.0^{\circ} \times 2.5^{\circ}$ & 01 & $26.1 \%$ & & 0.60 & 0.60 & 0.91 & $19.4 \%$ & 0.69 & 0.88 & -0.56 & 0.25 & -0.31 & 0.12 & 1.10 \\
\hline \multirow{3}{*}{ gfdlcm21 } & \multirow{3}{*}{$2.0^{\circ} \times 2.5^{\circ}$} & 01 & $29.2 \%$ & & 0.88 & \multirow{3}{*}{0.82} & 0.93 & $27.9 \%$ & 0.95 & 0.94 & -0.69 & 0.31 & -0.37 & 0.14 & 1.90 \\
\hline & & 02 & $32.0 \%$ & & 0.74 & & 1.02 & $23.6 \%$ & 0.61 & 0.93 & -0.72 & 0.31 & -0.37 & 0.18 & 1.08 \\
\hline & & 03 & $31.1 \%$ & & 0.78 & & 1.03 & $26.8 \%$ & 0.85 & 0.90 & -0.69 & 0.30 & -0.40 & 0.19 & 1.32 \\
\hline
\end{tabular}




\begin{tabular}{|c|c|c|c|c|c|c|c|c|c|c|c|c|c|c|c|}
\hline \multirow{2}{*}{ gissaom } & \multirow{2}{*}{$3^{\circ} \times 4^{\circ}$} & 01 & $36.5 \%$ & $15.7 \%$ & 0.41 & \multirow{2}{*}{0.42} & 0.58 & $24.0 \%$ & 0.49 & 0.75 & & & & & \\
\hline & & 02 & $24.5 \%$ & $15.5 \%$ & 0.37 & & 0.54 & $14.9 \%$ & 0.59 & 0.95 & & & & & \\
\hline \multirow{3}{*}{ gisseh } & \multirow{3}{*}{$4^{\circ} \times 5^{\circ}$} & 01 & $39.8 \%$ & & 0.66 & \multirow{3}{*}{0.68} & 0.92 & $29.2 \%$ & 0.79 & 0.83 & -0.52 & 0.19 & -0.28 & 0.10 & 0.38 \\
\hline & & 02 & $27.1 \%$ & $21.5 \%$ & 0.57 & & 0.65 & $18.3 \%$ & 0.82 & 0.81 & -0.50 & -0.01 & -0.28 & -0.04 & 0.54 \\
\hline & & 03 & $23.2 \%$ & & 0.68 & & 0.63 & $17.7 \%$ & 0.86 & 0.87 & -0.44 & -0.19 & -0.28 & -0.08 & 0.00 \\
\hline \multirow{4}{*}{ gisser } & \multirow{4}{*}{$4^{\circ} \times 5^{\circ}$} & 02 & $24.8 \%$ & & 0.47 & \multirow{4}{*}{0.49} & 0.64 & $14.9 \%$ & 0.41 & 0.83 & & & & & \\
\hline & & 03 & $27.9 \%$ & & 0.39 & & 0.71 & $14.6 \%$ & 0.19 & 0.87 & & & & & \\
\hline & & 04 & $31.0 \%$ & & 0.48 & & 0.74 & $16.3 \%$ & 0.56 & 0.83 & & & & & \\
\hline & & 05 & $23.3 \%$ & & 0.54 & & 0.66 & $16.0 \%$ & 0.60 & 0.79 & & & & & \\
\hline hadcm 3 & $2.5^{\circ} \times 3.75^{\circ}$ & 01 & $29.2 \%$ & & 0.87 & 0.87 & 0.92 & $27.6 \%$ & 0.96 & 0.93 & -0.73 & 0.14 & -0.41 & -0.01 & 1.14 \\
\hline hadgem1 & $\sim 1.3^{\circ} \times 1.9^{\circ}$ & 01 & $31.7 \%$ & $20.9 \%$ & 0.92 & 0.92 & 0.76 & $20.4 \%$ & 0.98 & 0.96 & -0.79 & 0.31 & -0.47 & 0.06 & 0.40 \\
\hline inmcm30 & $4^{\circ} \times 5^{\circ}$ & 01 & $36.2 \%$ & & 0.45 & 0.45 & 1.02 & $20.0 \%$ & 0.43 & 0.85 & -0.56 & 0.33 & -0.31 & 0.18 & -0.25 \\
\hline ipslcm4 & $2.5^{\circ} \times 3.75^{\circ}$ & 01 & $35.7 \%$ & & 0.45 & 0.45 & 1.09 & $21.0 \%$ & 0.67 & 0.71 & & & & & \\
\hline miroc32h & $\sim 1.1^{\circ} \times 1.1^{\circ}$ & 01 & $39.8 \%$ & & 0.74 & 0.74 & 1.03 & $34.1 \%$ & 0.87 & 0.88 & -0.67 & 0.39 & -0.36 & 0.15 & 0.12 \\
\hline \multirow{3}{*}{ miroc32m } & \multirow{3}{*}{$\sim 2.8^{\circ} \times 2.8^{\circ}$} & 01 & $33.5 \%$ & & 0.81 & \multirow{3}{*}{0.74} & 0.97 & $29.9 \%$ & 0.87 & 0.95 & -0.71 & 0.35 & -0.47 & 0.19 & 0.36 \\
\hline & & 02 & $29.0 \%$ & & 0.67 & & 0.89 & $24.4 \%$ & 0.81 & 0.86 & -0.60 & 0.28 & -0.31 & 0.10 & -0.74 \\
\hline & & 03 & $37.8 \%$ & & 0.71 & & 1.05 & $31.4 \%$ & 0.81 & 0.90 & -0.61 & 0.42 & -0.32 & 0.24 & -0.13 \\
\hline \multirow{5}{*}{ mricgcm 232} & \multirow{5}{*}{$\sim 2.8^{\circ} \times 2.8^{\circ}$} & 01 & $36.7 \%$ & $16.5 \%$ & 0.72 & \multirow{5}{*}{0.83} & 0.63 & $14.8 \%$ & 0.83 & 0.94 & -0.67 & 0.47 & -0.29 & 0.22 & 0.43 \\
\hline & & 02 & $26.5 \%$ & & 0.86 & & 0.79 & $24.8 \%$ & 0.88 & 0.97 & -0.78 & 0.43 & -0.42 & 0.14 & 0.87 \\
\hline & & 03 & $29.5 \%$ & & 0.78 & & 0.89 & $25.0 \%$ & 0.73 & 0.94 & -0.76 & 0.51 & -0.43 & 0.21 & 0.19 \\
\hline & & 04 & $29.3 \%$ & & 0.92 & & 0.81 & $27.9 \%$ & 0.95 & 0.96 & -0.75 & 0.44 & -0.40 & 0.18 & 0.25 \\
\hline & & 05 & $34.4 \%$ & & 0.74 & & 0.95 & $29.9 \%$ & 0.89 & 0.87 & -0.72 & 0.38 & -0.37 & 0.12 & 0.30 \\
\hline \multirow{4}{*}{ pcm } & \multirow{4}{*}{$\sim 2.8^{\circ} \times 2.8^{\circ}$} & 01 & $47.7 \%$ & & 0.88 & \multirow{4}{*}{0.90} & 1.61 & $45.2 \%$ & 0.96 & 0.92 & -0.82 & -0.03 & -0.56 & -0.10 & 0.12 \\
\hline & & 02 & $49.7 \%$ & & 0.90 & & 1.44 & $48.4 \%$ & 0.98 & 0.92 & -0.74 & 0.00 & -0.47 & -0.10 & 0.87 \\
\hline & & 03 & $49.8 \%$ & & 0.83 & & 1.41 & $45.9 \%$ & 0.95 & 0.88 & -0.78 & 0.04 & -0.48 & -0.08 & 0.09 \\
\hline & & 04 & $37.1 \%$ & & 0.93 & & 1.16 & $36.3 \%$ & 0.98 & 0.96 & -0.85 & 0.09 & -0.55 & -0.02 & -0.54 \\
\hline
\end{tabular}


(a) OBSERVED SLP

(b) MULTI-MODEL SLP

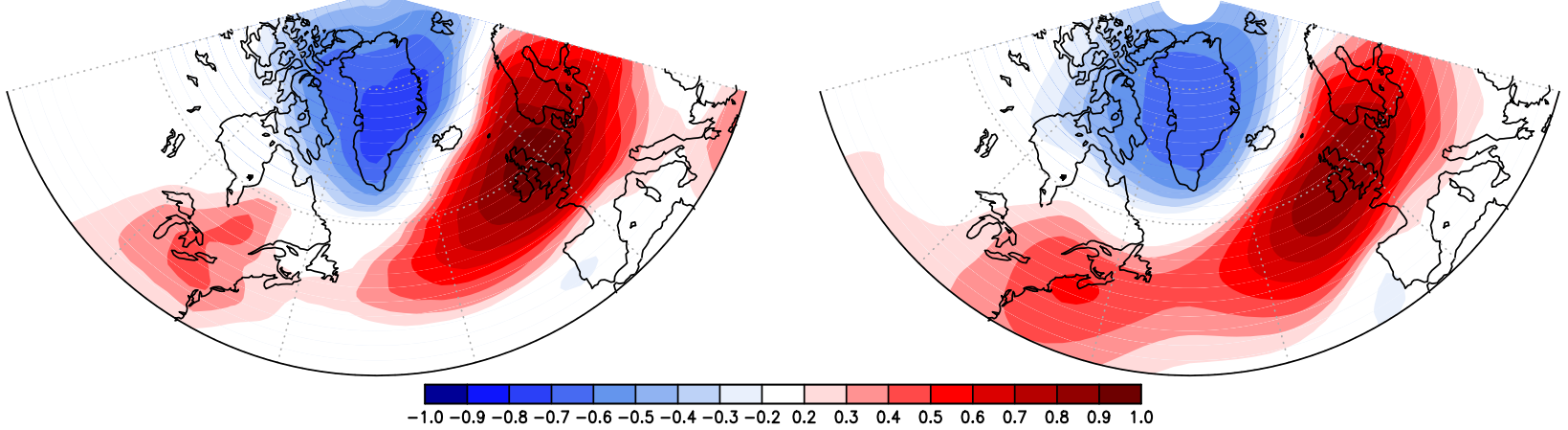

(c) OBSERVED PRECIPITATION

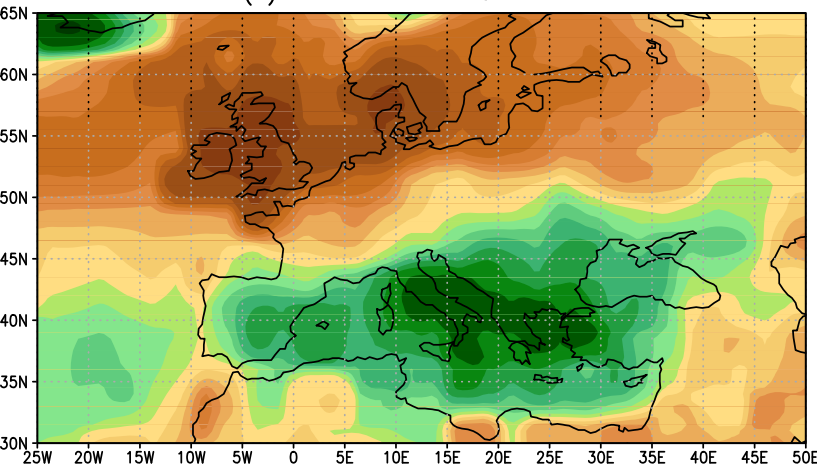

(d) MULTI-MODEL PRECIPITATION

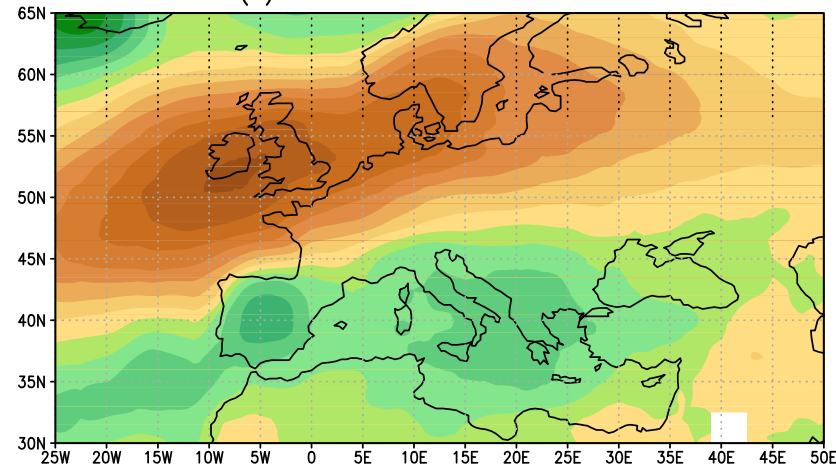

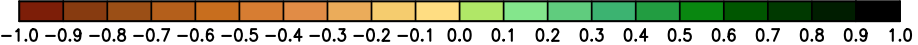

(e) OBSERVED Z200

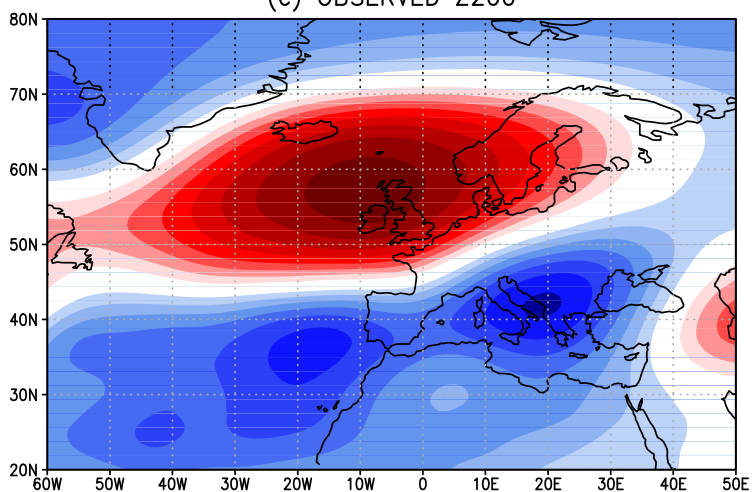

(f) MULTI-MODEL Z200

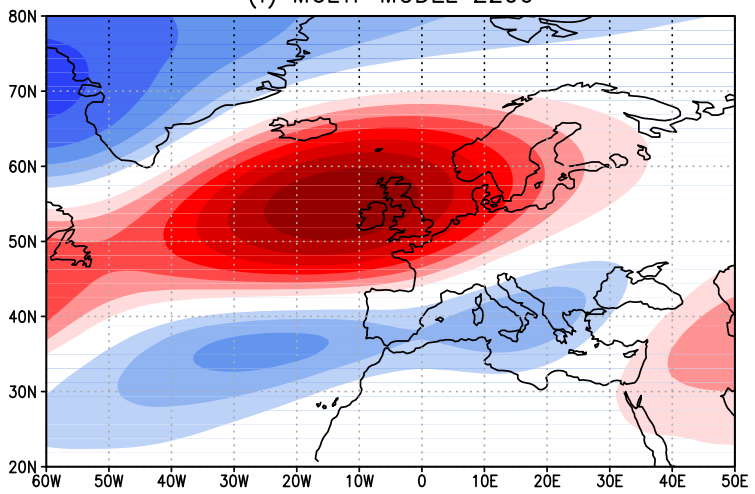


CORRELATION SNAO VS. PRECIPITATION

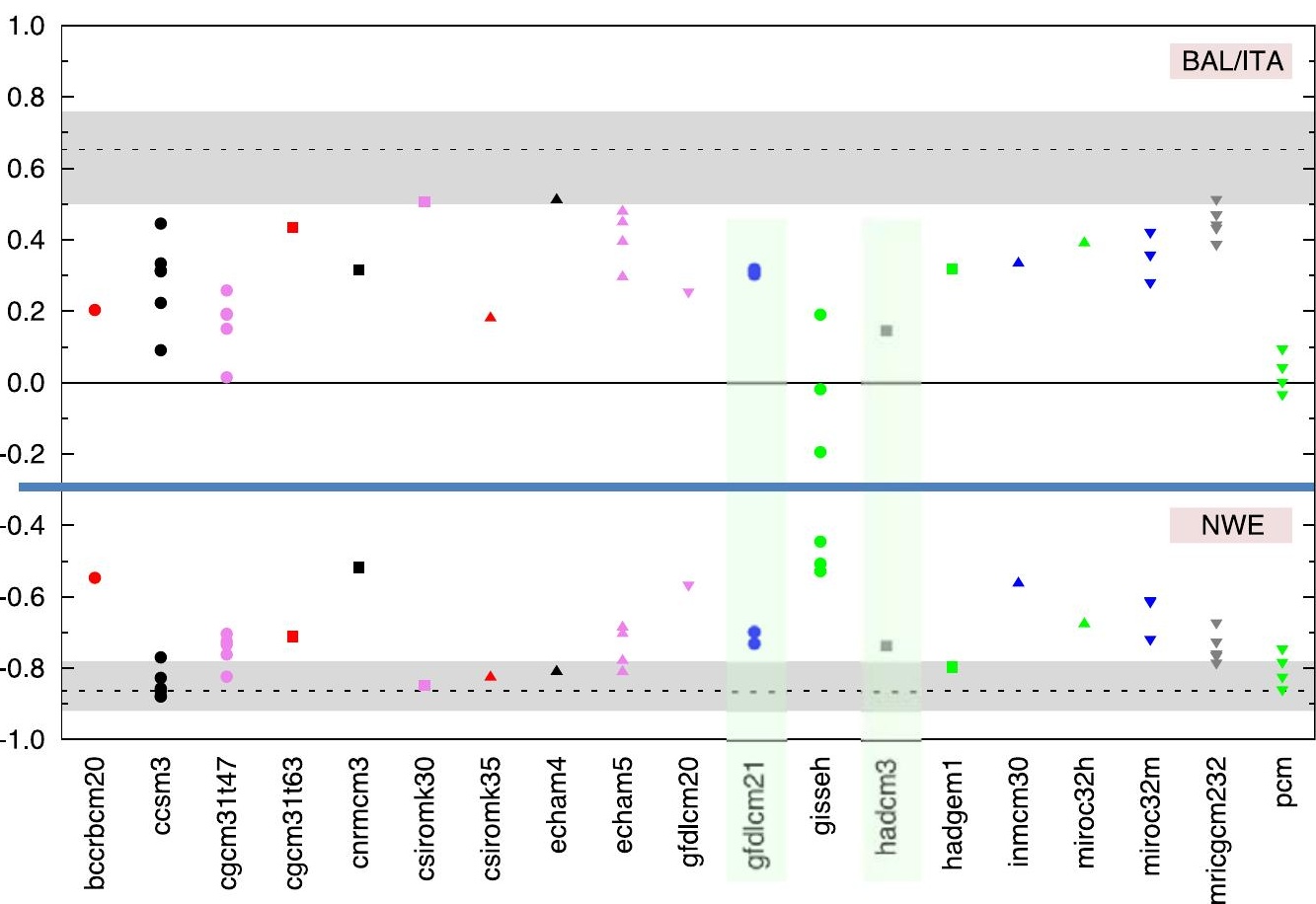




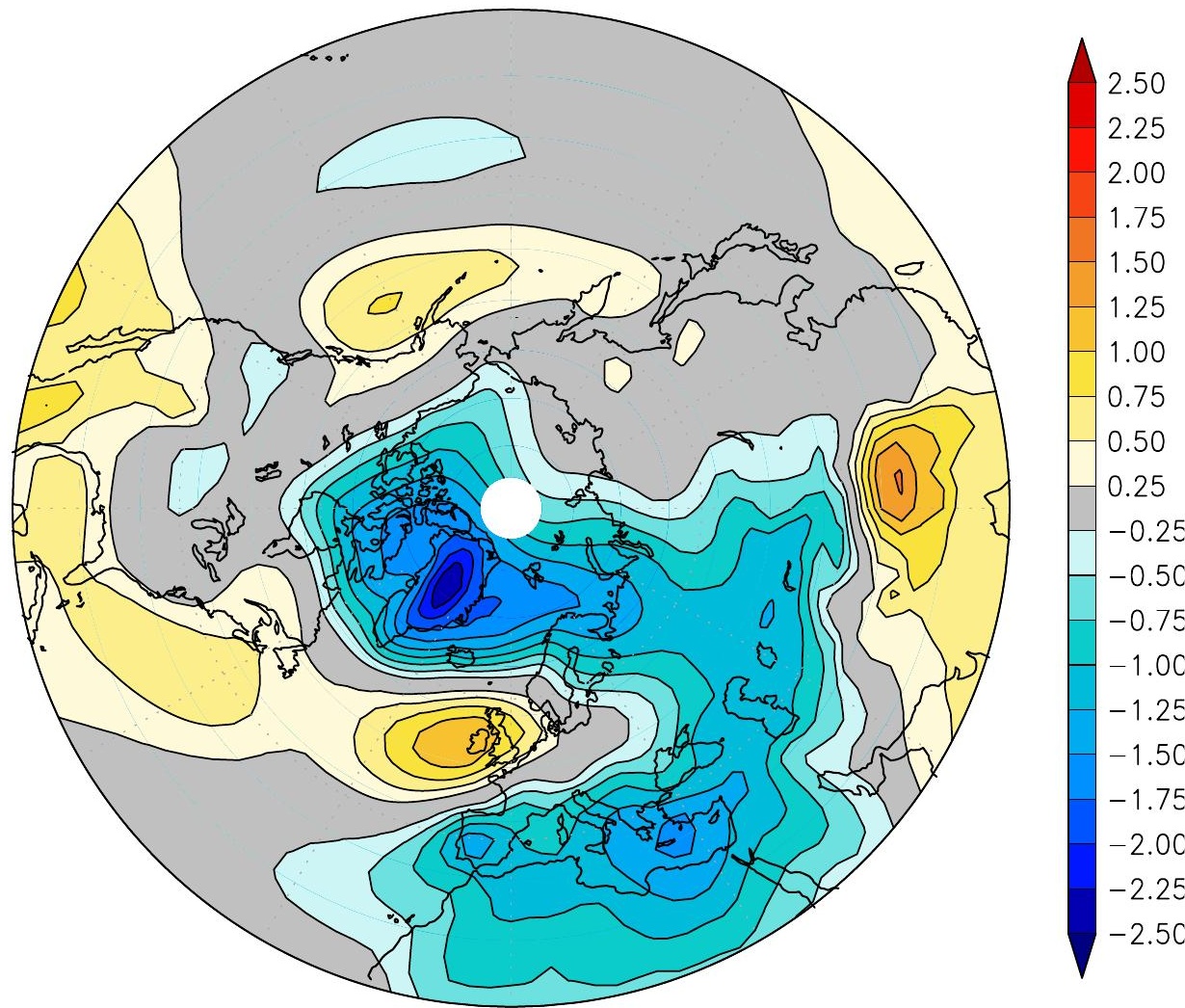


SNAO INDUCED MULTI-MODEL PRECIPITATION TREND

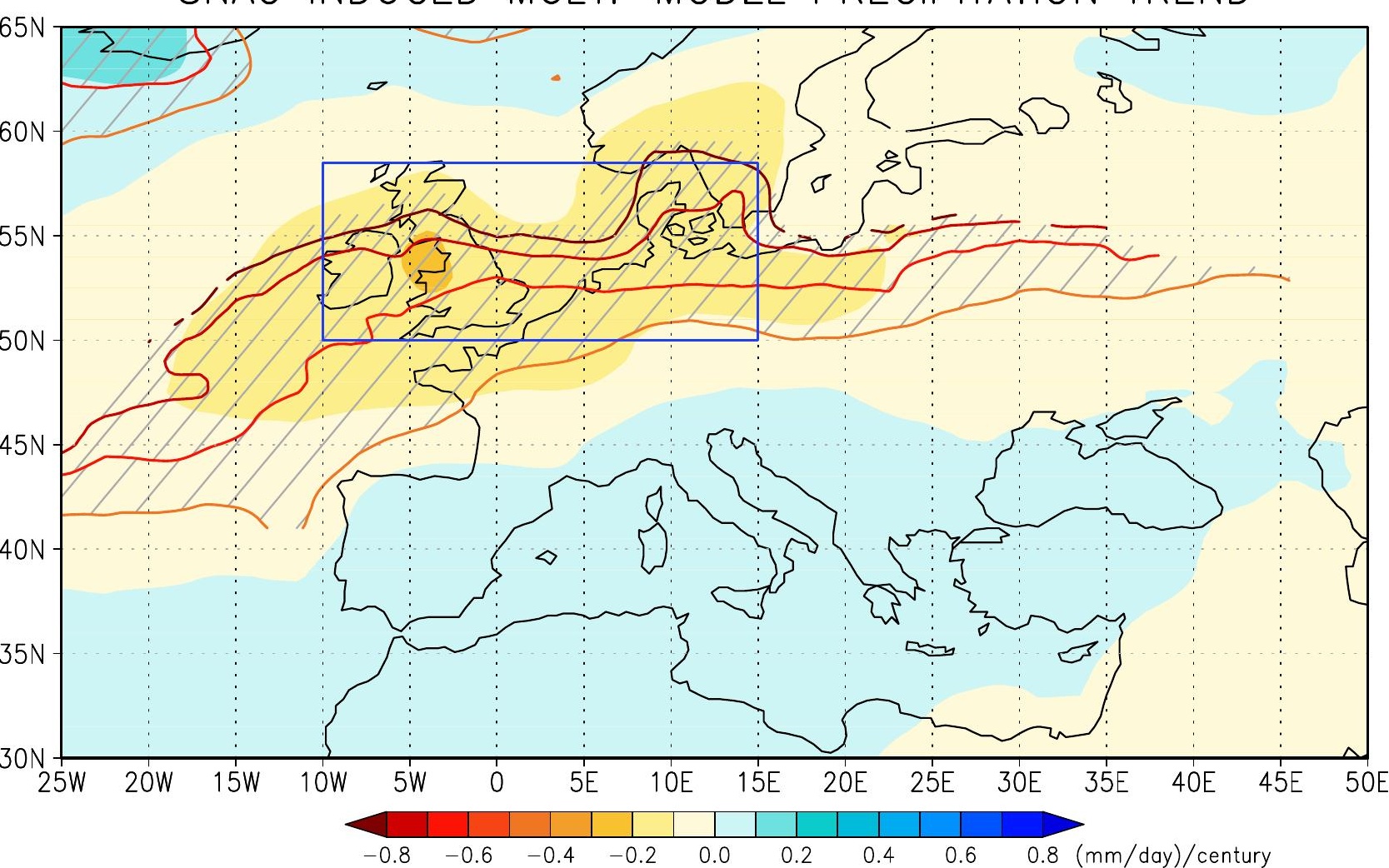


(a) NWE-2 PRECIPITATION AND SNAO TRENDS (2010-2099)

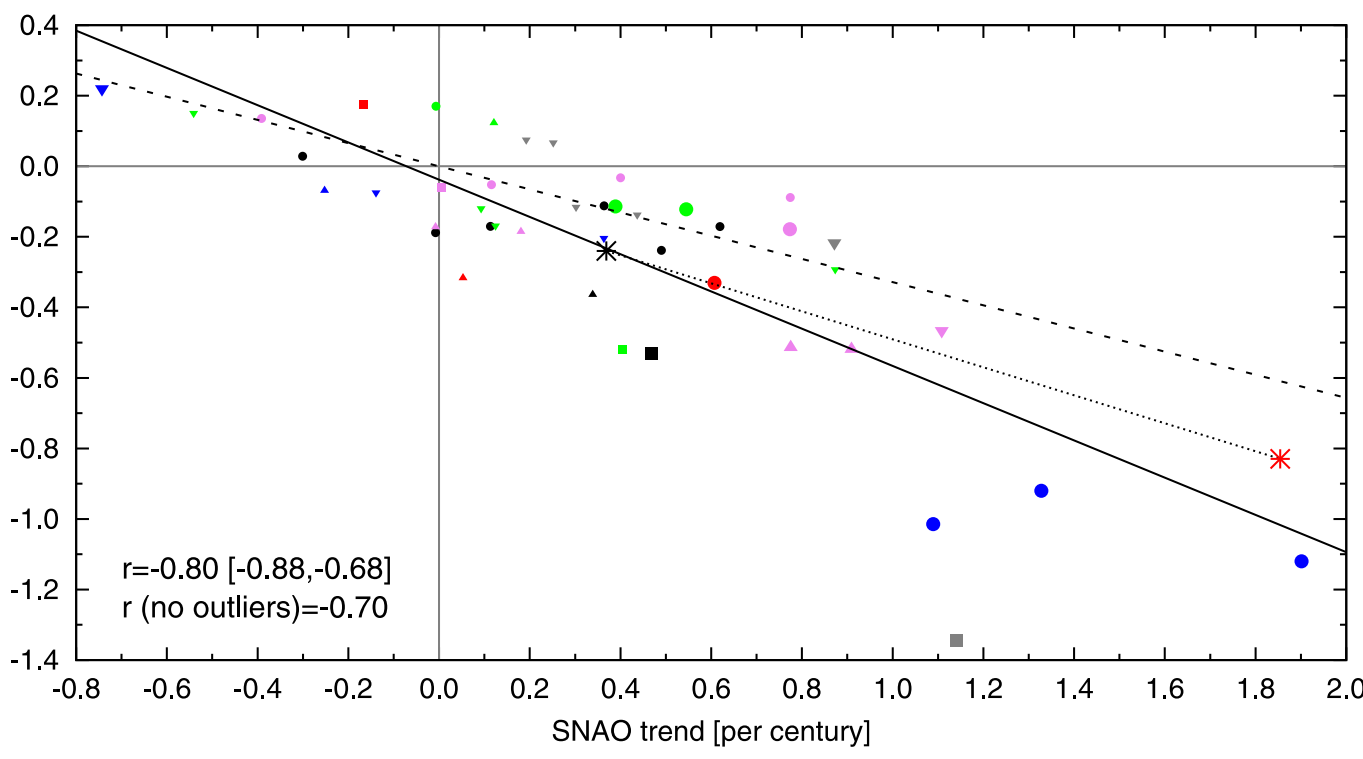

(b) BAL/ITA PRECIPITATION AND SNAO TRENDS (2010-2099)

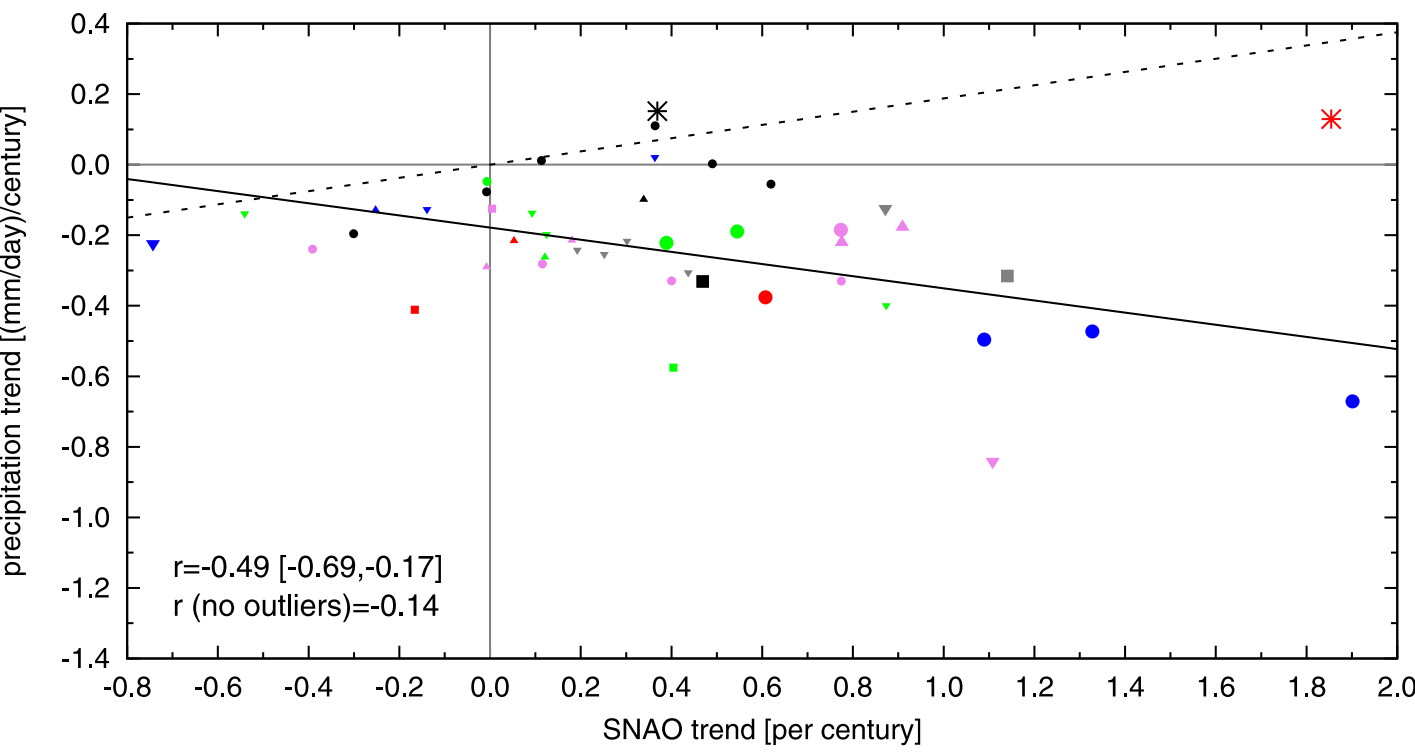

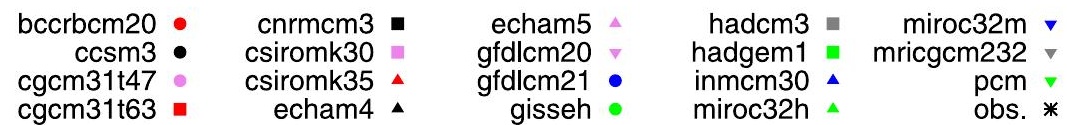

